\title{
Preparations to Terrorist Chemical Weapons Threats: From Malaysian Perspective
}

\author{
${ }^{1}$ M. Vikneswaran, ${ }^{2}$ Norizan Abdul Majid and 2Zuhairee Ariffin Assan
}

${ }^{1}$ Faculty of Engineering, National Defence University of Malaysia, 57000 Kuala Lumpur, Malaysia.

${ }^{2}$ Ministry of Defence, 50634 Kuala Lumpur, Malaysia.

Correspondence Author: M. Vikneswaran, Faculty of Engineering, National Defence University of Malaysia, 57000 Kuala Lumpur, Malaysia, Tel: +6019-3004742; E-mail: vikneswaran@upnm.edu.my

Received date: 12 February 2018, Accepted date: 20 June 2018, Online date: 2 July 2018

Copyright: (C) 2018 M. Vikneswaran et al. This is an open-access article distributed under the terms of the Creative Commons Attribution License, which permits unrestricted use, distribution, and reproduction in any medium, provided the original author and source are credited.

\begin{abstract}
Malaysia is a multiracial country with background of different races, religions and cultures. Even though, Malaysia has yet to face any major terrorist attacks, the risk is always there, and we should prepare for the uncertainties. In the historical perspective, chemical warfare agents (CWAs) have never been used or released in a larger scale since World War I by any parties even if they are capable of doing so. At present, the major threats are seen originating from the militant, radical or terrorist groups with intentions to use CWAs to create unrest and instability. The Tokyo Subway Sarin Attack in the morning of March 20, 1995 is a classic example how the CWAs were used onto general public by a radical group to create panic and chaos. Based on that incident, this paper will try to gain understanding of the events and learn valuable lessons from the Tokyo Sarin attack and will try to simulate if similar situation occurs anywhere in Malaysia. Therefore, this paper highlighted various points of view related to the cooperation between national agency, Standard Operation Procedure (SOP) and even the source of CWAs ingredients available in Malaysia. The study had reviewed various important documents and interviewed leaders of various agencies to study the overall pattern of chemical weapon threats and the preparation to defense which is based on qualitative research. This paper able to give some insights on how to handle such attacks and the steps that could be taken if CWAs are being released by some groups of people in an area.
\end{abstract}

Key words: Chemical Weapon, Terrorist, Threat, Chemical Warfare Agents

\section{INTRODUCTION}

The events of terrorist attack onto Tokyo subway stations on $20^{\text {th }}$ March 1995 that left 12 commuters dead and more than 5000 injured, showed that that CWAs are easily available to any group as the knowledge to produce such agents are accessible through literatures and internet [1-2]. Furthermore, the possibilities of emerging radical, international terrorist network and cunt group to produce CWAs should not be underestimated as they are also actively sharing the tips and manual for the production of the chemical agents [3]. In Malaysia's surroundings, Toxic Industrial Chemicals (TICs) that can be easily applied as CWAs are in abundance due to existence of many chemical industries here [4]. Thus, the establishment of databases and factory listing that produces, uses or storing TICs as their industrial based materials should be made available to facilitate monitoring in preventing misuse of such substances or the possibilities of the TICs being smuggled out by irresponsible parties and used as the ingredients to produce CWAs.

Since 1993, Malaysia has signed the Chemical Weapons Convention (CWC) treaty and became a member state of Organizations for Prohibition of Chemical Weapon (OPCW). Due to that, this nation has the privileges to access for support and assistance from the organization if there is a CWAs attack. What are the consequences that could happen if Malaysia is suddenly attacked by chemical agents? The Article X of OPCW treaty stated that duration of arrival for international assistance would be within five hours. Depending on the types of agents, the most volatile agent can stand up to five hours. Hence, this nation should have to rely on its own expertise within the first crucial five hours. Therefore, there is an importance to study how Malaysia should react and manage the situation to prevent further disaster and secondary contamination to the general public and the first responder. Similar studies may already be discussed but not properly documented as yet.

This study reviewed the Sarin attack at Tokyo Subway stations in 1995. Thus, one of the objective is to study the lessons learnt from Japan's experience in managing the incident that could be later be applied if such incident happens in Malaysia. The main objective of this study is to create awareness and to gauge the preparedness of our first responder to handle a chemical attack of CWAs. It is an importance as even a well-developed country such as Japan encountered difficulties in handling the chaotic situation from the Sarin attack making a nation such as Malaysia of no exception. The study also had discussed the current Malaysian Fundamental Law on Disaster Management and its suitability that can be a review for any scenarios related to CWAs attack or TICs major mishandling incident.

LITERATURE REVIEW:

Since the incident of Highland Tower collapse on $18^{\text {th }}$ May 1994, the Malaysian government learnt that effective mechanisms and guidelines should be established to prevent conflict, mismanagement, confusion and overlapping roles among the national agencies. In response to the incident, the government through Malaysian National Security Council (NSC) in 1997 had published fundamental guidelines of disaster management. One of the fundamental guideline stated that in case of any chemical related disaster, the Fire and Rescue Brigade will be assigned as the lead agency responsible for the disaster. However, based on Japan experience on the subway station Sarin attack, the Tokyo Metropolitan Police and the Tokyo Metropolitan Fire Department at that time did not have the enquired capabilities to handle such a large-scale disaster and lack of coordination between both agencies lead to agencies carrying out their roles separately. The Japanese 
Self Defense Forces, that has the knowledge on CWAs and decontamination ability, was not called at the early stage that resulted to confusion in the rescue operation and exposed the first responders to secondary contamination. The response from Japan Self Defense Forces came in late, as they cannot act without the consent of the Prime Minister, which will be a similar situation for Malaysia's Armed Forces.

As highlighted by Taneda [5], the confirmation of the Sarin as neurotoxin agent used in the Tokyo subway attack was not available until several hours after the attack. This caused a chaotic situation due to a sudden surge in numbers of patients in hospitals where casualties from Sarin attack was transferred because hospital staffs are yet to receive any complete information about the actual cause before a treatment plan could be provided. Fortunately for St. Luke's International Hospital, the response was based on the assumption that the cause was a nerve agent as advised by a physician who had experienced Matsumoto incident before. On that reliable information from Japan Self Defense physician the hospital management deliberately prepare a treatment plan that was established soon after the attack. The St. Luke hospital personnel were fortunate enough to get accurate advice before establishing the treatment plan. Since hospital personnel in Malaysia never before dealt or experience of any such nerve agent attack, confusions and delays may occur in the process of establishing the treatment plan. This paper will study the level of awareness and preparedness of the public hospital.

Secondary contamination on first responders and hospital personnel was also a major problem during Tokyo Sarin attack. During the incident, Personnel Protective Equipment (PPE) was only distributed to the first responder and virtually no PPE had been provided to the medical personnel at the hospitals responding to casualties of Sarin attack. This resulted to approximately $23 \%$ of the hospital staff at St Luke's International Hospital experiencing secondary contamination. The root cause of the problem was absence of PPE for hospital personnel and failure to decontaminate the casualties before transferring and admitting them to the designated hospitals. The decontamination line should have been set up on-site in warm zone or within hospital open area. However, when dealing with large-scale and mass casualty situation, it will be difficult to set up a mass decontamination line to cater for the public. The Japan special units and their resources at that time were not designed to cater for the situation that involves thousands of casualties. In this study, options to use public facilities for mass decontamination and its execution were also discussed below.

\section{METHODOLOGY:}

This study used qualitative research method through case study. The military assessments approach such as Military Appreciation Process (MAP) and Intelligent Preparation of Battlefield (IPB) were used to compliment qualitative research method. To support that the primary and secondary sources of literature were used to accomplish the study. There are mainly from books, official government administration publications, journals, conference paper publications, working paper presentations and speeches. Other than that, few interviews with Malaysian security agencies give an insight of some practical application in terms of chemical weapon usage in Malaysia.

\section{CHEMICAL WEAPON TERRORISM READINESS:}

In Malaysia, the National Security Council (NSC) under the Directive No. 20 governs the management of disaster: Policy and Mechanism of Disaster Management and Relief Committee (National Security Council Directive). This policy is an executive order from the Honourable Prime Minister that was issued on $11^{\text {th }}$ May 1997. The Directive interpreted "Disaster" and "Non-disastrous Incidents".

The Prime Minister's department is the country's highest national administration on decision and policy making in relation to the national security. The National Security Division (NSD) comes directly under the Prime Minister's department as the leading agency regarding security matters in the country, which is extended to the state, district and community levels parallel to the development structure.

Royal Malaysian Police (RMP) is the main government body that is responsible in maintaining the Law and Order in Malaysia. The Malaysian Armed Forces (MAF) role on the other hand is to ensure nation's sovereignty and defend Malaysia against foreign military invasions or penetration. In certain circumstances, the police may require aid in discharging their task in which MAF given the responsibility to be in action [6]. In maintaining public order, the Public Order Manual (POMAN) is available and applicable for military and police authorities as one of the documented policies for commanders at all level in planning and executing their task. This will help to prevent and deter the terrorism activities from taking place in any condition.

An internal security problem is a situation when an imminent threat is identified or developed into an armed insurgency. This will be ceased to be a Public Order (PO) situation. The threats to PO may originate from any of the following sources such as racial / Communal Issues, religious issue, political agitation, economic issues, educational issues and industrial disputes.

Terrorist or subversive elements may take this as opportunity to serve their own purposes. This may be to defeat the Government's agenda or to provoke community against both the Special Force (SF) and the government by driving or forcing the imposition of unpopular or repressive measures. In most of the cases the prevention is better than cure. Therefore, Malaysian government always believes that the planning and execution of current and future security measures is important to maintain the PO. The listed legislations for the maintenance and restoring PO's in the country are Penal Code S. 141 (FMS CAP. 45) (3), Police Act (2), 1967, S. 27 (5), PO (P) O 1958 (12), Industrial Act, 1967 (15), Education (School Discipline) Regulations, 1959 (2), The Explosive Ordinance, 1957, The Protected Areas and Protected Place Ordinance, 1959 (20), The Arms Act, 1960 (22), The Fisheries Act, 1963, S. 10 (1) and The Internal Security Act, 1960, etc.

The Civil Defense Department is one of the responsible agencies to response to larger scale of national disaster or emergency. This agency involvement will help to decrease the damage or harm involving human lives and civilian property before, during, and after a disaster occurrence. The main role of the Civil Defense Department is to provide assistance and support in disaster or crises situation. Even so, there is a need to be clarified here that the Civil Defense is not the only agency that takes part in the rescue and aid. Other agencies and organizations are also involved and cooperate with each under the authority guidance in completing tasks given. It is the norm that such collaboration will involve services of public health, fire-brigades, the security forces rescue troops and the technical public utilities. Thus, the responsibility and their assignments in protecting the local community remains unchanged with exception to armed conflict.

In term of protective measures in case of disasters and emergencies especially when chemical attack is concerned, the most importance action is an individual protective. The civil defense will be assigned to build indoor protection; protection in the cellar for unprepared or prepared shelter and execute evacuation on a small scale. Under the Laws of Malaysia Act 221, Civil Defence Act 195, Civil Defence forces may be ordered to perform relief and rehabilitation work.

The Director General for Civil Defence may with the concurrence of the minister order the Civil Defense Forces or services or any part there to be employed for performance of any relief work or giving protection to or taking measures for ensuring the safety of the lives, the event of any disaster or impending disaster or of affecting of facilitating their rehabilitation after such disaster [7].

The familiar motto "Preventing is better than healing" gives definite meaning in the efforts of protecting Malaysia population from any kind of emergency including terrorist activities. In view of this, it is in Malaysia's best interest to ensure that peaceful situation is the first priority for the country in line with the global peace. By taking cognisance as its strategic and competing interests, Malaysia's defense policy revolves around the fundamental principles of Self-Reliance, Regional Co-operation and External Assistance [8]. With escalating terrorist activities and establishment of terrorist networks in different parts of the world, a multilateral response to terrorism would seem to be the appropriate approach to combat terrorism. As noted, the co-operation with different countries is great necessity to the efforts to suppress terrorism, as terrorist attacks worldwide in recent events has caused tremendous psychological and economic effects to many countries. Eight types of response can encounter chemical weapon terrorism namely awareness, laboratory preparedness, plan in place, individual \& collective protection, detection \& characterization, emergency response, measures to protect the public's health and safety and treatment and safe practices.

Recent development in terrorist activities has increased concern for a potential chemical weapon attack which can cause mass casualties. Therefore, a particular attention is needing to be given to scenarios with potential in which a chemical agent can be intentionally released among civilians. Thus, various drastic changes shall be introduced to contain the possible impact of particular agent and its source.

The first step that need to be considered is the prevention step that is important in the counter measure and control of terrorism activity in chemical weapon. The federal government chemical defense efforts should be driven by several strategy and planning documents. These efforts involve many different governmental agencies with each specific role that implemented numerous disparate actions and programs within their statutory areas in addressing the threat. Despite these efforts, many experts, including congressional commissions, non-governmental organizations and industry representatives has highlighted weaknesses or flaws in the federal government chemical defense activities. Therefore, there is a need for research and development through inter-agencies cooperation, which includes Prime Minister Department, Ministry of Defense, Ministry of Health and other relevant agencies that are viable in these processes. 
The second step involves multiple public health interventions in which are possible in this context to effect contamination containment. It includes a requisition of imposition for large-scale or geographic quarantine on the potentially exposed population. Although large-scale quarantine has never been experienced in Malaysia before, but it has been used on a small-scale for simulated chemical weapon terrorism exercises. Besides that, the public health also has to be strong and capable in encountering all the impact from a chemical agent attack.

All concerned agencies and government instrumentalities carried out their respective functions to ensure that the following measures shall be considered; Supervision and implementation of policies and actions of the government against terrorism; Intelligence co-ordination; Internal focus against terrorism; Accountability of public and private corporation and personalities; Synchronization of internal efforts with a global outlook Legal measures; Promotion of religious solidarity; Vigilance against the movement of terrorist and their supporter's equipment, weapons and funds; Contingency plans; Comprehensive security plans for critical infrastructure; Support of overseas Malaysian worker or students; Modernisation of the Malaysian Armed Forces (MAF) and the Royal Malaysian Police (RMP), and also other government agencies involved directly to the counter terrorism roles; Media support; and Measures taken on politic, social and economic issues.

The paper suggests considering the following measures in connection with the government's commitment and cooperation in the international struggle against terrorism. They are join the international counter-terrorist coalition and work with the United Nation (UN), work closely with the other countries on intelligence and security matters concerning terrorism, make available Malaysian airspace and facilities if the latter are required as transit or staging points, contribute logistical support in the form of food supplies, medicine and medical personnel, subject to the concurrence of the Malaysian cabinet, provide combat troops and prevent the flow of funds to terrorist groups.

The basic key questions faced in the decision-making process by governmental policymakers for chemical weapon terrorism are first; how sufficiently do the efforts already underway to address the threat of chemical weapon terrorism? Second; have the federal investments to date met the expectations of government or other stakeholders? Third; should government alter, augment, or terminate these existing programs in the current environment of fiscal challenge? Finally; what is the appropriate federal government role in response to the threat of chemical weapon terrorism, and what mechanisms are most appropriate for involving other stakeholders, including state and local jurisdictions, industry, and others?

The entire question above will make the federal government to have a proper strategic planning, risk assessment, surveillance and its development, procurement, and distribution of medical countermeasures.

\section{CONCLUSION:}

The internal security agencies, armed forces and other agencies need to work together to ensure safety arising out of any chemical weapon threats. It is also the responsibility of the individual to know the safety measure and aware of such incident. Now, if any chemical agent attacks were to occur, the main concern is to avert or contain such emergencies.

Planning and preparation in advance for chemical terrorism can help to minimize potential public health and environmental threats if and when an actual emergency occurs. During the planning process, emergency response organizations makes assessment on how they would respond to each type of incident and the resources that will be needed to react according to the incident. In Malaysia, the planning and preparation for response to chemical weapon terrorism involve many parties. In the event of a chemical weapon terrorism disaster, the National Security Council, the Malaysian Armed Forces, Internal Security Force and the Ministry of Health will work together with other federal agencies, state and local governments, first responders and international organizations to monitor the situation, contain the release and prepare the quarantine facility if needed. Throughout the response, each of the responsible agencies practices their respective protective action guidelines.

The first essential step in developing a containment strategy is to determine if the threat at hand is communicable. In any chemical weapon threat, the containment will be effectively achieved using methods that do not attempt to contain large groups of people. During large-scale chemical weapon threat, decision makers would be critically dependent on the availability of timely accurate information about what is happening and what interventions are desirable and feasible. Effective information dissemination would work to suppress rumors, anxiety and enlist community support.

Total defence concept involves all the governments' machinery assets and suitable effort in overcoming terrorist challenge that can jeopardise the national security. Proper structured organization chart, clear term of reference and coordination between the relevance agencies in preparedness of chemical weapon terrorism attack or any emergency, can reduce large casualties and reduce damage to the nation.

The chemical terrorism is unique and need to be managed carefully and precisely. Chemical weapon terrorism impacts impose heavy demands on the strength of the government, security forces, public health care system and the research and development strategies of a country. This is what is demanded by the general public upon the governmental agencies that manage the consequences. An effective preparation and responding process to counter measure chemical weapon terrorism activity during emergencies is need to be prepared. This is followed by strong prevention, detection and response strategies, which are required to counter any act of covert or overt chemical weapon terrorist attack. Defenselessness and capability, two prerequisites of chemical weapon terrorism, are in place.

Enhancing preparation and responding process will help us deter and defeat deliberate the targeted chemical agent's impact, as well as increase the general health and well-being of the population. The intention of potential attackers is difficult to manage. Therefore, limiting our vulnerability is the most promising way to prevent or mitigate chemical weapon attacks that the country is confronting.

\section{REFERENCES}

[1] Ledgard, J.B., 2014. A Preparatory Manual of Explosive. $4^{\text {th }}$ Edition. UVKCHEM. USA

[2] Ledgard, J.B., 2006. A Laboratory History of Chemical Warfare Agents. $2^{\text {nd }}$ Edition. UVKCHEM. USA.

[3] Hoette, T.M., 2012. Systems Analysis of Past, Present and Future Chemical Terrorism Scenarios. Sandia National Laboratories.

[4] Bruce, E., A. Chanlett and R. Cronin, 2009. Terrorism in Southeast Asia. Congressional Research Service, 7-5700, RL 34194 www.crs.gov

[5] Taneda, 2005. The sarin nerve gas attck on the Tokyo subway system: Hospital response to mass casualties. Traumatology, the International Journal, $11(2)$.

[6] AF Code, T., 1971. 1025 / Police 15, The Public Order Manual (POMAN), The Manual for The Police And Armed Forces On The Maintenance Of Public Order. Issued by Royal Malaysian Police Headquarters and The Ministry of Defense.

[7] Laws of Malaysia Act 221, Civil Defence Act 1951 (Revised 1979).

[8] Abdul Ghani, Y., 1995. The Malaysian Armed Forces and Vision 2020 in Abdul Razak Baginda \& Rohana Mahmood, Malaysia's Defence \& Foreign Policies, Kuala Lumpur: Pelanduk Publications, p: 3. 